\title{
Vision, identity, and collective behavior change on pathways to sustainable futures
}

\author{
Ilan Chabay ${ }^{1,2}$ (i) \\ Published online: 23 November 2019 \\ ๑) The Author(s) 2019
}

\begin{abstract}
The challenge facing humanity is to live sustainably within both the ecological and physical limits of our planet and the societal boundaries needed for social cohesion and well-being. This is fundamentally a societal issue, rather than primarily an environmental problem amenable to technological optimization. Implementing the global aspirations embodied in the sustainable development goals of the United Nations will require societal transformation largely through collective behavior change at multiple geographic scales and governance levels across the world. Narrative expressions of visions of sustainable futures and narrative expressions of identity provide important, but underutilized insights for understanding affordances and obstacles to collective behavior change. Analyzing affective narrative expressions circulating in various communities seeking to implement aspects of sustainability opens up the opportunity to test whether affectively prioritized agent-based models can lead to novel emergent dynamics of social movements seeking sustainable futures. Certain types of playful games also offer the means to observe collective behaviors, as well as providing boundary objects and learning environments to facilitate dialogs among diverse stakeholders. Games can be designed to stimulate learning throughout the life span, which builds capacity for continuing innovation for the well-being of societies in moving toward sustainable futures.
\end{abstract}

Keywords Sustainable development goals - Collective behavior change Narratives Affective narrative expressions · KLASICA · Agent-based models · Playful games for serious purposes

JEL Classification $\mathrm{Q} \cdot \mathrm{Z}$

Ilan Chabay

Ilan.chabay@iass-potsdam.de

1 Institute for Advanced Sustainability Studies, Potsdam, Germany

2 Barrett \& O’Connor Washington DC Center, Arizona State University, Tempe, AZ, USA 


\section{Context and challenge}

Humanity faces a host of critical challenges arising from patterns of living unsustainably in nearly all contemporary societies. These challenges that exist on global to local scales have been related to fundamental limitations of resources, failures in governance of commons, population growth, and to the risk of transgressing critical bio-geo-physical conditions in the Planetary Boundaries perspective (Rockström et al. 2009; Steffen et al. 2015a, b). The "Anthropocene Era" (Crutzen 2002) captures the planetary conditions and humanity's increasingly profound role in shaping them. It is both a marker of human impact in transforming the Earth and crucially a call to recognize the need to address the consequences of a changing relationship between our conception of and response to the interplay between social and ecological systems.

The similar patterns of abrupt increase and accelerating rate of change in environmental and social phenomena, shown in the "Great Acceleration" graphs (Steffen et al. 2015a, b), adds urgency to the need to change these patterns. In light of these challenges that humanity faces, a safe and just operating space for humanity can be visualized as a "doughnut" (Raworth 2017) or annulus between minimal societal needs in multiple dimensions and the ceiling characterized by the Planetary Boundaries logics.

Increasing recognition of the multiple challenges facing human societies led to the approval by the United Nations in 2015 of the 17 sustainable development goals (SDGs) and 169 targets for 2030 (United Nations General Assembly 2015). Setting and agreeing on these goals represent a remarkable and significant step forward by 193 nations. The SDGs are important, because they represent the aspirations agreed upon by all countries for a sustainable future with equity and justice. However, the exact meaning of sustainability, as well as of equity and justice, and the means, governance, and monitoring of progress toward the goals is not agreed upon or shared globally. The exact interpretation of the SDGs and targets and the means of implementing them are open to interpretation by nations and also to questions of priorities in defining and implementing them at the regional and local levels.

These arguments and ambitious goals-whether from a natural science or a social science perspective-have helped drive essential discussions of the current and possible future conditions on our planet and in our society and how to shape responses to these challenges. To go beyond these boundary perspectives and stimulate further valuable discourses and actions, this paper draws attention to visionary, normative, and cultural dimensions in play in societies seeking sustainable futures. In considering visions and goals to address the unprecedented changes occurring, a boundary to be overcome rather than avoided is freeing our imaginations from the constraints of what has been done and paths that have been followed. This also opens the conversation to humanities scholarship and arts by bringing in imagination or imaginary worlds (Bendor et al. 2015) and esthetic, moral, legal, spiritual, and philosophical perspectives.

As important as the agreement and efforts toward the SDGs are, there are substantive concerns that must be addressed in acting on them. One is that the SDGs 
represent a complex array of critical issues, which are fundamentally interdependent through multiple connections, and thus require consideration in holistic frameworks, rather than isolated compartments. A second difficulty is the assumption inherent in the SDGs that "achieving the vision underpinning the SDGs will be possible on the foundations of our current global socioeconomic system and its natural environment" (TWI2050-The World in 2050, 2018, Chapter 2). A third concern, also as expressed in the TWI2050 report (ibid), is that "Globalism threatens the future of governance because it disenfranchises many and empowers a technocratic elite. It also stimulates the emergence of identity issues, which in turn give rise to conflict and polarization." I will return to issues of identity later in this paper in the context of narratives of vision and identity. In addition, an essential question is how societal changes on the scale needed can be implemented through a combination of top-down direction and bottom-up individual and collective behavior change at multiple spatial scales and governance levels.

As noted above in regard to the Anthropocene Era, human actions are substantially responsible for the fact that we are living in the midst of accelerating, unprecedented, and complex global to local changes. Consequently, it is both critical and urgent that we change our collective behaviors with concomitant changes in norms and cultural patterns in societies from current unsustainable behaviors and onto pathways to sustainable futures appropriate in each culture and context.

\section{Collective behavior change}

Both individual and collective behavior change is necessary for moving to sustainable futures (Rauschmayer et al. 2015). Individuals independently changing their behaviors are certainly important not only for the contribution of the actions themselves, but also for indicating and reinforcing the sense that the individual may have about contributing to a better future. However, acting as an individual may leave the person feeling ineffectual or frustrated for several reasons. Complexity may obscure the causes of a problem they want to solve, high uncertainty and the difficulty in detecting and assessing the consequences of their individual actions can be strong disincentives for action. In addition, behaviors undertaken by individuals often may be uncoordinated, inconsistent, or opposed to actions of other individuals and thus become ineffective to some degree. Even if no less uncertain or indeterminate in assessing outcomes, collectives may provide individual members with incentives and support to maintain commitment to the shared purpose or goal.

Choosing and following potential pathways for societal change that can diminish the negative impacts of human actions and mitigate or adapt to the changes to which it continues to contribute means that we must recognize the fundamental relationship between society and the bio-geo-physical systems on Earth. Though human society is inextricably embedded in the natural systems on which it is entirely dependent, different societies define for themselves what is relevant and valuable in their relationship to the local and global environment (Ignatow 2006), including ecology, biodiversity, and resources, and whether humankind is considered a part of or standing apart from nature. Sustainability in the sense of the social, economic, 
and environmental pillars (Brundtland Our Common Future 1987) thus depends on how people conceive of their relationship to the environment and therefore also their sense of individual and collective agency and responsibility to act in support of the three pillars of sustainability.

Individuals, communities, and institutions need more than a strong sense of agency and responsibility or the decision to take a single concerted effort at one point in time in one context. Continual processes of learning, designing, and innovating to address the needs for societal well-being in diverse contexts are needed. Thus, the crucial challenges to be addressed are imagining sustainable lifestyles, institutions, and processes for societies (Bendor et al. 2017; Beckert 2013), designing and acting for continuing change, rather than only attempting to avoid or mitigate inevitable changes (Bai et al. 2019). The priority shifts to learning and organizing changes in human behavior and norms, particularly changing collective behaviors, rather than focusing solely on mitigating the consequences and path dependencies of unsustainable behaviors. For example, rather than changing behaviors through alternatives, such as public transportation and pedestrian paths, relying on mitigating excessive energy consumption by increased efficiency of appliances or vehicles may be defeated by a rebound effect leading to increased use of energy (Azevedo et al. 2013; David Tàbara et al. 2018).

\section{Living in complex systems}

These are particularly difficult challenges, because society as a complex system itself exists within highly complex ecological, geological, and physical systems on Earth. Humankind has profoundly changed the systems on our planetary home and must now realign and reassert itself in new ways to avoid catastrophic consequences of further changes. Thus, we must learn, innovate, negotiate, and navigate on pathways toward sustainable futures within complex systems and therefore cope with (1) inescapable uncertainty - due to undetermined causalities in multiply coupled nonlinear systems, (2) normative ambiguity-due to co-existing value systems and thus differences in interpreting information, and (3) unintended or unanticipated consequences - due to impacts of unrelated events and to the temporal and spatial dispersion of feedback loops (Renn et al. 2011).

Coping with complexity requires expertise, perspectives, and methods from a wide range of disciplines, including social sciences, natural sciences, and humanities (e.g., law, history, art, philosophy, ethics), as well as a wide range of sources of knowledge - traditional, cultural, and local. While deep expertise in the narrowly focused channels of disciplines is and will remain necessary, that alone is not sufficient to address the challenges of living in complex social-ecological systems. We also must use complex systems concepts and sustainability science to engage in an integrative, holistic approach to knowledge generation and implementation (de Vries 2012; Miller et al. 2014). Equally importantly, we need to engage openly and respectfully with the knowledge and creativity of the peoples of the world, without which we would be deprived of important opportunities to find new, emergent perspectives and creative solutions. 
The SDGs provide consensus aspirations in a global vision for the future in 2030, but on a more granular local or regional scale, what visions are there that indicate a desirable target state and incentives for collective behavior change toward those goals? And what motivates individuals to join and support the collectives or to remain outside or oppose them? How does or can collective behavior change occur in different cultures and contexts? How can social movements for long-term, intergenerational, social-ecological sustainable futures with justice and equity be catalyzed and supported? What factors enable or hinder formation and efficacy of such social movements?

Understanding the characteristics, dynamics, and influences of social movements and collective behavior change toward sustainable futures form the research domain of the Knowledge, Learning, and Societal Change Alliance (KLASICA). ${ }^{1}$ KLASICA was founded in 2008 by the author and is currently based in and supported by the Institute for Advanced Sustainability Studies in Potsdam, Germany. Researchers affiliated with KLASICA seek to understand how knowledge, meaning making, and societal change are interconnected and in particular to:

1. Identify and understand conditions under which collective behavior change toward sustainable futures occurs (or fails) in different communities, cultures, and contexts.

2. Build models based upon narrative expressions to improve understanding of dynamics of societal movements to sustainability and potentially unexpected (emergent) patterns of collective behavior or consequences thereof.

3. Use that understanding to advance solutions for and promote actions on pathways to sustainable futures.

\section{Narratives of vision and identity}

Throughout our existence, humans have created, spoken, sung, painted, danced, and acted narratives to express significant experiences, visions, and elements of their beliefs. Narratives are stories with a sequence of events, actors, scene or context, which serve a function for an individual or the society beyond the storytelling itself (Brown 2017; Westerhoff and Robinson 2013). For example, narratives may instruct the young and maintain culture and cultural identity or shape political or religious dialog and movements.

Visions are often powerfully expressed in narratives that not only define a desirable future, but also serve to shape and reinforce commitments of the individuals and groups to the common goal expressed in the narrative. Narratives of identity express the sense of the individual as a part of or distinct from a social group, community or society (Amel et al. 2017; Worchel and Coutant 2008; Kahan et al. 2007). Narrative identity provides indications of motivation that have a substantial influence on

\footnotetext{
1 https://www.iass-potsdam.de/en/research/knowledge-learning-and-societal-change-alliance-klasica.
} 
decisions by individuals for joining a particular group or community and acting in accord with the group.

Narratives of identity are contextually rich stories that individuals hear and tell themselves and others about their experiences and the significance of the family or group histories. The stories sum to a narrative that characterizes the individual in society with respect to many attributes, often co-existing in one individual, for example, community of faith, profession or job, and family history. Belonging to and acceptance by a group or community as reflected in social identities also provide motivation for acting in accord with the intentions of the group. By the same token, identifying with the narrative of one group may emphasize alienation from another group and thus motivation for strongly opposing or outright rejecting views or actions of the "others".

Margaret Somers in "Narrative construction of identity: a relational and network approach" (Somers 1994) writes "... it is through narrativity that we come to know, understand, and make sense of the social world, and it is through narratives and narrativity that we constitute our social identities." She also makes the important statement that "...narrative identity approach assumes people act in particular ways because not to do so would fundamentally violate their sense of being at that particular time and place."

\section{Affective expressions of narratives}

The core ideas of discourses that encapsulate worldviews, dreams or fears, and reflections of identity of individuals or communities also often appear as condensed affective expressions with strong emotional communicative power. As condensed expressions they are memorable and often circulate readily in the society even when the original, extended discourse is not easily recalled or perhaps not even known to many. In the current age of pervasive social media, narrative expressions have circulated as memes and undergone successive evolutionary steps allowing them to resonate with and influence different groups and communities. These condensed narrative expressions take many forms. A well-known example is the long, powerful, eloquent speech by Martin Luther King, Jr. (King 1963), which contained the phrase "I have a dream." That speech energized the civil rights community. The phrase alone has served to keep alive a sense of shared purpose, even when the substance and eloquence of the speech itself was no longer remembered.

In addition to narratives in written and spoken forms, visual, kinesthetic, and musical forms are also prevalent and powerful in evoking affective responses by connecting with aspects of particular contexts and stories. One example is the mural painted by Picasso in 1937 that graphically evoked the horror of war in the bombing of Guernica. Another visual image in shown in Fig. 1 of a house in Taiwan honoring the memory of a lost village.

Two dance performances choreographed by Cassie Meador entitled "Drift" and "How to Lose a Mountain" depict, respectively, the "relationship of people to places, to history, and to their food" and "a story that has been lived and a distance that has been traveled" of the products people use (https://cassiemead 


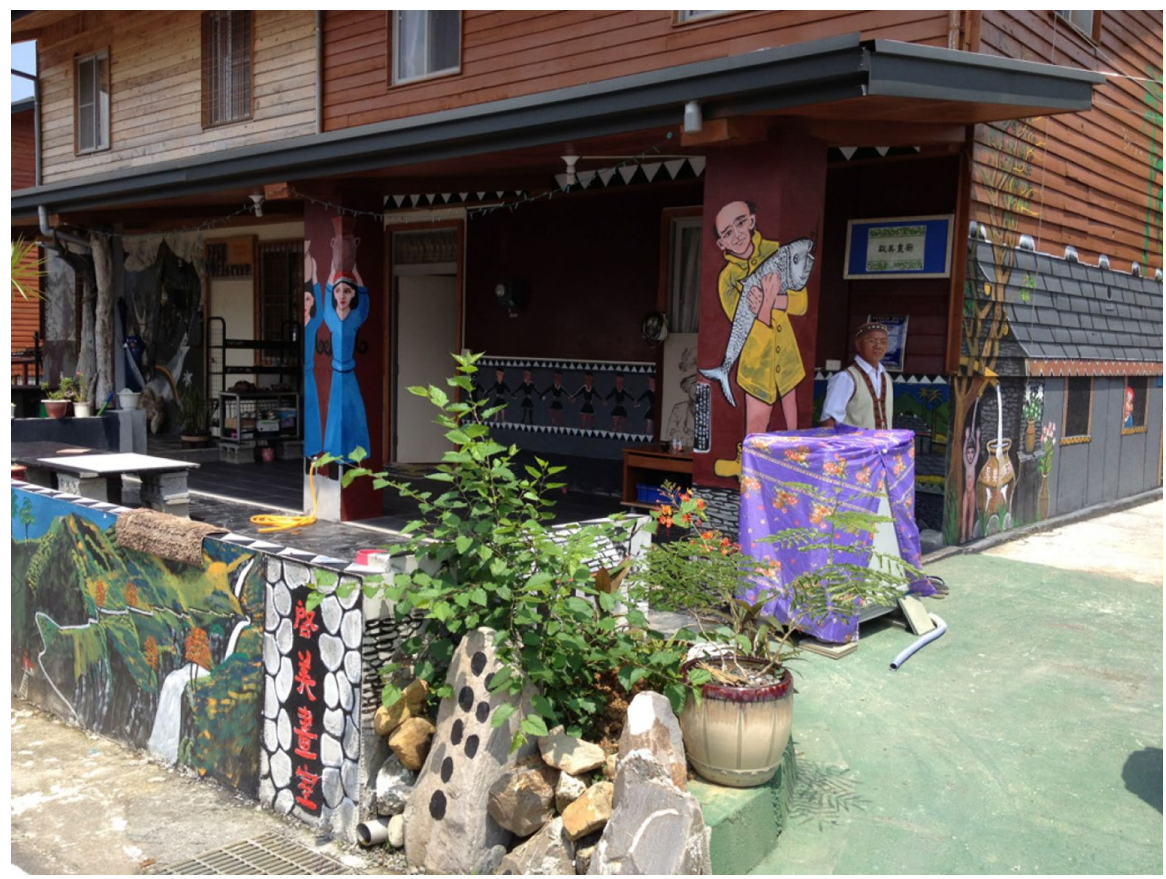

Fig. 1 The murals on the house and low wall in an indigenous community in Majia Township, Taiwan, were created by the artist to help children and adults to remember and honor the culture and way of life of their previous village buried by a landslide (photo (C) Ilan Chabay 2012)

or.wordpress.com/projects/). Both the mural in Taiwan and the dance performances are strongly affective artistic expressions reflecting each artist's perspective on significant issues and in turn forming memorable experiences to engage viewers in reflecting anew on salient matters of sustainability in their contexts.

These positive examples are in contrast to expressions that explicitly characterize sustainability as a threat to American exceptionalism. For example, laws were passed in Alabama and Kansas that rejected the call for sustainability in the voluntary guidelines of the UN's Agenda 21 in 2012 (Berry and Portney 2017; Frick et al. 2015) and Trump's exhortation for a putative return to greatness of America by disengaging from global efforts, including the Paris climate change accords of 2015 (Selby 2019; Saad 2018).

All these examples show the forms and purposes to which the condensed affective narrative expressions (Chabay et al. 2019) have been used to motivate people, whether for or against a particular choice of action. While it is increasingly important to consider how they could be used to overcome the alienating and divisive trends currently escalating across the world, it is beyond the scope of this paper to examine this in detail. In general, the author believes that this can be addressed in local or regional contexts by identifying and amplifying existing positive narratives or stimulating new locally resonant narratives. 


\section{From narratives to social dynamics models}

With these narrative expressions in mind, KLASICA researchers are looking more deeply into narratives of vision and identity that represent goals and motivations to understand more clearly the nature and trends in the dynamics of social movements tied to aspects of sustainability. Massively increased computational power along with "big data" may allow us to seek and discover critical distinctions and nuances, not only statistical measures of movements and activities in their contexts. Narrative expressions provide information that can be analyzed for critical qualitative insights and become a basis for societal modeling that provides a range of plausible options and associated consequences of choices for decisions and actions.

That was the challenge addressed in the second Taipei KLASICA symposium in Fall 2018, namely, to understand goals, motivations, and dynamics of social collectivities acting for or opposing certain sustainability-related goals. The symposium was structured to collect and categorize examples of narratives of vision and identity that guided or motivated actions by a community wishing to address a relevant aspect of sustainability in the local context. This was the entry point to exploring the suitability of motivations inferred from narratives to identifying rules for agents in modeling of social dynamics. The selected narratives had a universal or at least transcultural, as well as an idiosyncratic component. One of the main challenges was to identify and understand the distinctive characteristics of these two components.

The following five analytic concepts for categorizing narrative expressions were proposed (Renn 2019):

1. the type of evidence that is expressed in the narrative to make the it plausible and convincing (associative plausibility),

2. the setting, scope or context to which the narrative is connected (framing),

3. the core value(s) the narrative affirms or links to (normative affirmation)

4. elements in the narrative that stimulate emotional responses from the listener/ viewer (emotional identification)

5. stimulated affect responses that motivate action (motivational incentives)

The purpose of our modeling of social dynamics is to open up our creative thinking about plausible future patterns of change, timelines, and bifurcations in pathways toward sustainability. We aim to use approaches and build tools, including agent-based models, for creative thinking that may stimulate socially relevant innovation. The model outputs can be used as the basis for sets of scenarios that explore options for decisions and associated plausible consequences for each option. The production of scenarios based on projections of future biological, physical, or economic conditions is not new. What is new is the opportunity to explore the influence of the affective landscape on decisions in addition to other conditions in the scenarios. 


\section{Learning to change}

Changing at the rate and scale that the challenges imply means that the processes of learning in society will also need to change rapidly, difficult as that is. Changing behaviors toward sustainable societal patterns requires that the entire "educational ecosystem" from children to parents and grandparents to teachers and administrators also becomes engaged in learning to learn in ways that support sustainable futures. This process of learning starts with early childhood learning and continues across the entire life span. These processes must be reflected not only in the formal educational systems with all the world's heterogeneity in goals, governance, methods, and curricula, but also in the very important informal or "free-choice" learning sector (Falk 2005; Facer 2011; Rogoff et al. 2016). It is essential to reach throughout societies, sectors, and ages to build awareness of the urgent and critical challenges, share knowledge, and develop culturally and contextually appropriate innovative solutions for well-being of societies. The opportunities are vast in social media and games, though at the same time, these media can be and are being used to reinforce unsustainable consumption and destructive actions in society. The challenge is in continuing to develop media, experiences, and games to engage people of all ages and life contexts in activities that open their awareness and thinking about sustainable futures relevant and desirable in their lives. Museums, zoos, aquaria and other public spaces are important venues in which people are invited to engage in activities that offer new ideas and facilitated dialogs on important local issues (e.g., Hennes and Chabay 2001).

Behavioral change for sustainability will require shifting education:

- from results of models to the models themselves to understand the results, rather than just remember them and to grasp the process of science as a way of examining the world;

- to inquiry and experiential learning that can effectively engage people of all ages by stimulating their questions, nurturing curiosity, and supporting ownership of ideas;

- to looking for multiple solutions appropriate to the context and values of the relevant community, rather than only seeking a singular optimized solution;

- to a process of learning by collaboration with diverse styles, perspectives, capabilities;

- to encourage intellectual risk taking and not expect (or be expected) to succeed every time.

\section{Playful games for serious purposes}

In informal learning environments, as well as in formal educational settings, games can provide playful experiences in which central ideas become relevant and useful. Play, including with games, can be more than entertainment. Many 
animals, including humans, play as an essential process of learning skills, managing relationships, and testing limits. Playing games designed to actively involve children or adults and to stimulate questions and nurture curiosity can provide effective and memorable learning experiences (Honeyford and Boyd 2015). The games can be playful experiences for serious purposes, including stimulating thinking, creative expression, and problem solving. Some games or game-like activities function as boundary objects that are able to engage a range of stakeholders holding different views, knowledge, power, and resources. In bringing together and engaging those stakeholders with their divergent views and different contexts, the boundary object focuses attention on the object or shared activity in the dialog, rather than being directed primarily at other participants. The game, as a boundary object in a "safe" space for exploration and experimentation, offers an opportunity to enhance empathy and understanding of the challenges faced by different individuals and communities seeking a sustainable future with justice and equity in their context.

Three types of games, selected from many forms and variants, are designed in different ways and with different purposes to engage players in exploring and learning about aspects of sustainability and complex systems, including imagining and designing sustainable societies. One form is a platform for specific experimentation with an underlying model. The user can tune certain parameters critical to the functioning and dynamics of the system. This provides safe grounds for (typically technocratic) experimental problem solving. This type of experimentation is also fertile ground for collecting and analyzing data on decision making, as is being done in decision theaters (Boukherroub et al. 2018; White et al. 2010).

A second type consists of games or exhibition pieces designed primarily to engage the non-expert and expert alike with memorable, easily accessible experiences that stimulate curiosity and facilitate engagement with a very limited set of core ideas. In this approach, the model behind the game is intentionally simple, rather than inclusive or detailed, and focuses on illuminating the rather few ideas essential for a basic understanding. Most importantly, the experience serves to stimulate questions, awareness, and interest. This is done well by using dynamic, surprising (often cognitively dissonant), and multi-sensory ways that become memorable for the player. The game or exhibit then is a playground that should quickly engage and inspire users by highlighting the core ideas to which people easily relate. On an elementary level of content, it can also serve as a problem-solving playground and as boundary object for stimulating inquiry and dialog. For example, Kreyon City (Fig. 2) is a prototype of "Gaming the Future", which the author designed to illustrate through participatory activity that simple actions on a complex system have both intended-but not necessarily local and immediate-results, as well as unintended consequences. An aspect of Gaming the Future is that it would allow coupling of exhibition landscapes between different locations to engage people in different locations in an open dialog on specific aspects of sustainability and the process of making decisions on complex socio-ecological systems.

Stimulating dialog was also the intention behind the energy exhibits and German energy transition (Energiewende) game in a mobile exhibition mounted in expanding trailer truck in Germany (Fig. 3). The truck traveled around in Germany with the 


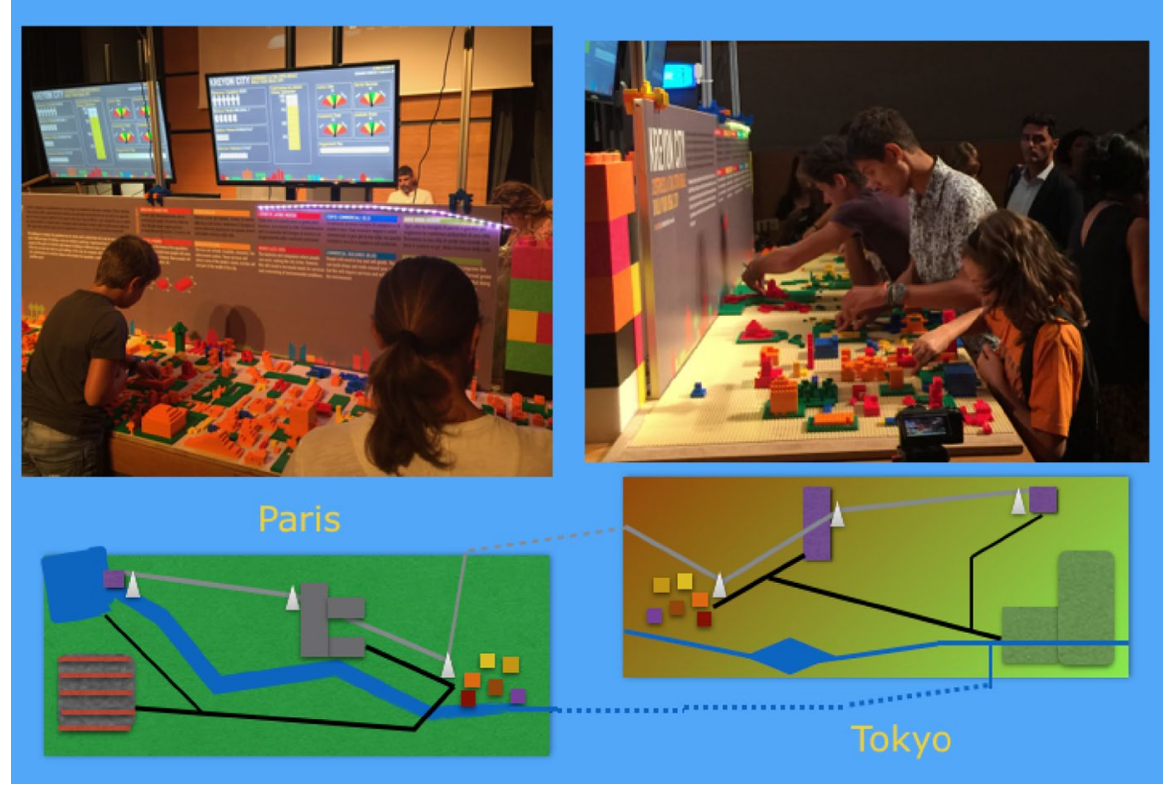

Fig. 2 Upper two photos show "Kreyon City" developed by Dr. Bernardo Monechi and Professor Vittorio Loreto being tested in Rome September 2017. It shows a prototype of the augmented reality "Gaming the Future", in which consequences of simple actions on complex systems in the local game board (and in a future version, also in a remote game board schematically indicated in the lower part of the image) are visualized (photos (C) Ilan Chabay 2017)

set of exhibits and a game designed by the author and Professor Ortwin Renn (Li et al. 2015). In the period between 2013 and 2018 the Baden-Württemberg Foundation reported that nearly 700,000 people visited the truck. Interactive physical exhibits on energy and power, sources of energy and its transmission, storage, and environmental impacts were placed around the truck's interior perimeter. In the center was a game that up to seven people could play for about $4 \mathrm{~min}$, during which all power demanded by the players for their energy consumption in their virtual homes in a virtual town was supplied by a player turning a hand-cranked generator. The lack of coordination in demand for power from the virtual homes of the players led to high peak demands and thus power outages. This provoked discussions of what can be done to flatten the demand curve and how that relates to use of renewable energy sources.

A third type of game being designed by the author has the potential to reach a very large number of people worldwide and draw them into a virtual world where they engage in intriguing encounters with some of the real challenges of rapid global to local change. The game (current working title: Heroes of Our Futures or HOOF) would engage people over an extended time in a massive multi-player online roleplaying game (MMORG). It will be a narrative-driven, role-playing adventure game built on the narratives of vision and identity from many communities, cultures, and contexts across the world woven together in a vast landscape. These separate quests in the stories require learning (in easily digestible chunks) and using acquired 


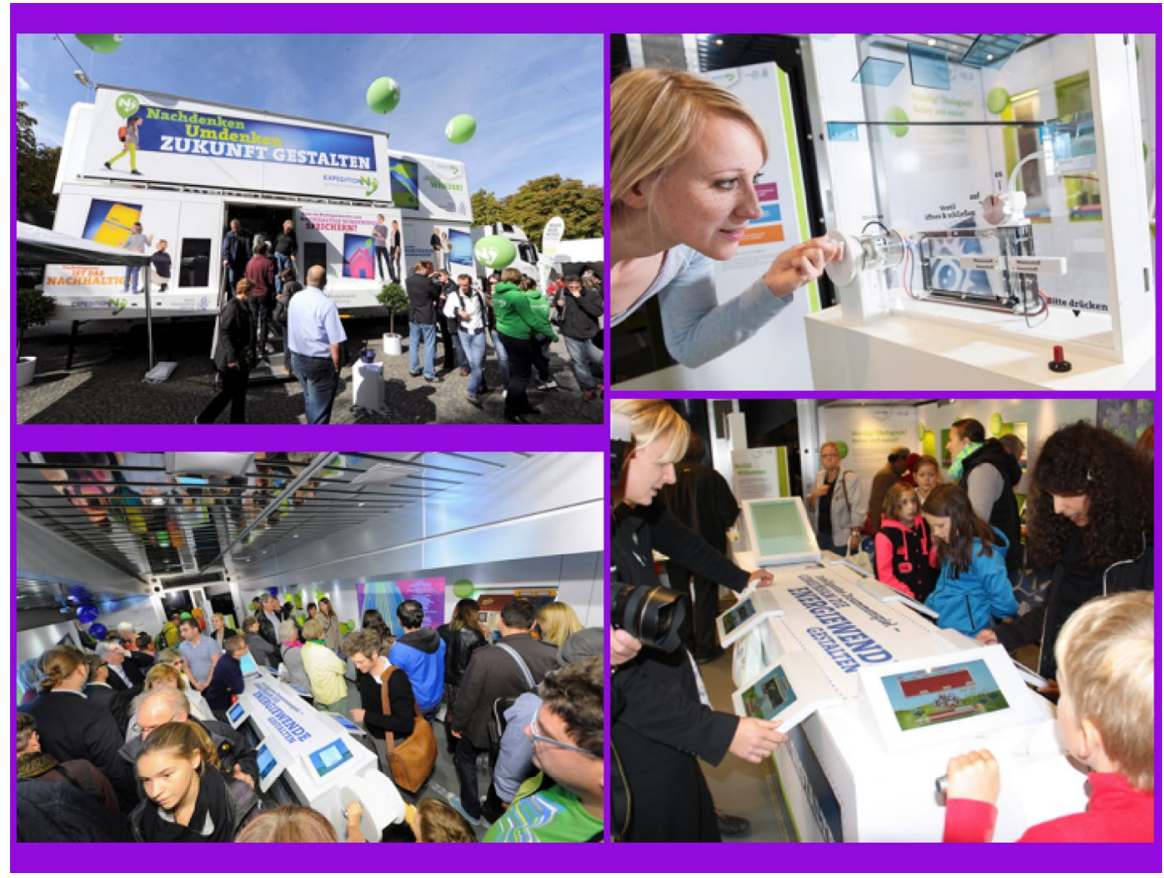

Fig. 3 A traveling exhibition on the energy transition in Germany containing exhibits on energy sources, transmission, storage, and impact on sustainability. In the center of the vehicle (lower right photo) is a multi-player game on household energy demand with renewable energy and coal as sources (photos (C) Ilan Chabay 2013)

local knowledge and norms to be successful in that quest. The player can use the increasing knowledge, reputation, and resources gained in quests to exert increasing influence and impact in their encounters. The idea of HOOF takes much from MMORG "dungeons and dragons" games, but with real-world political, economic, social challenges addressed by negotiating and problem solving in the game. That leads to acquiring resources, reputation, and influence, rather than increasingly powerful swords and sorcery (though a magic wand and powerful spells are seductively appealing in the face of dysfunctional governance, devastating conflicts, and unsustainable practices).

\section{Conclusion}

The profound challenges of global change in the Anthropocene Era have led to the adoption of the UN Sustainable Development Goals. To make substantial progress toward implementation of these 17 interdependent goals requires the use of interdisciplinary complex systems sciences and humanities plus transdisciplinary research methods and, at the same time, increasing meaningful engagement with the 
wide range of stakeholders at local to regional and national scales. This integrative approach is essential to understand and catalyze changing collective behaviors at multiple spatial scales and governance levels. The case was put forward that narrative discourses and condensed narrative expressions of vision and identity provide insights and an opportunity to explore the influence of the affective landscape on dynamics of social movements through agent-based models. Playful games for serious purposes also offer valuable insights and services when they are designed and used as boundary objects and learning environments to facilitate dialogs among diverse stakeholders. Using games to stimulate learning throughout the life span opens opportunities to build capacity for continuing innovation for the well-being of societies in moving toward sustainable futures.

Acknowledgements I am grateful to Professor Kaoru Takara, Dean of the Graduate School of Advanced Integrated Studies (GSAIS) at Kyoto University for the invitation to deliver the lecture that formed the basis of this paper and to Professor Yuichi Ikeda, GSAIS, Kyoto University and Guest Editor of Evolutionary and Institutional Economics Review for encouraging the submission of this paper. I also want to express my thanks to two reviewers for their insightful questions and comments.

\section{Compliance with ethical standards}

Conflict of interest The author states that there is no conflict of interest.

Ethical approval This article does not contain any studies with human participants or animals performed by any of the authors.

Open Access This article is distributed under the terms of the Creative Commons Attribution 4.0 International License (http://creativecommons.org/licenses/by/4.0/), which permits unrestricted use, distribution, and reproduction in any medium, provided you give appropriate credit to the original author(s) and the source, provide a link to the Creative Commons license, and indicate if changes were made.

\section{References}

Amel E, Manning C, Scott B, Koger S (2017) Beyond the roots of human inaction: fostering collective effort toward ecosystem conservation. Science 356(6335):275-279. https://doi.org/10.1126/scien ce.aal1931

Azevedo IL, Sonnberger M, Thomas B, Morgan G, Renn O (2013) The rebound effect: implications of consumer behaviour for robust energy policies. International Risk Governance Council, pp 1-36 (ISBN 9782970077244)

Bai X, Begashaw B, Bursztyn M, Chabay I, Droy S, Folke C, Gupta J et al (2019) Changing the scientific approach to fast transitions to a sustainable world. Improving knowledge production for sustainable policy and practice. IASS discussion paper. https://doi.org/10.2312/iass.2019.018

Beckert J (2013) Imagined futures: fictional expectations in the economy. Theory Soc 42(3):219-240. https://doi.org/10.1007/s11186-013-9191-2

Bendor R, Salter J, Sheppard S, Vattanawong O, Wang A, Williams S, Anacleto J et al (2015) Sustainability in an imaginary world. Interactions 22(5):54-57. https://doi.org/10.1145/2801039

Bendor R, Maggs D, Peake R, Robinson J, Williams S (2017) The imaginary worlds of sustainability: observations from an interactive art installation. Ecol Soc. https://doi.org/10.5751/ES-09240-22021 7

Berry JM, Portney KE (2017) The Tea Party versus Agenda 21: local groups and sustainability policies in U.S. cities. Environ Polit 26(1):118-137. https://doi.org/10.1080/09644016.2016.1219026 
Boukherroub T, D'amours S, Rönnqvist M (2018) Sustainable forest management using decision theaters: rethinking participatory planning. J Cleaner Prod. https://doi.org/10.1016/j.jclepro.2018.01.084

Brown P (2017) Narrative: an ontology, epistemology and methodology for pro-environmental psychology research. Energy Res Soc Sci 31(June):215-222. https://doi.org/10.1016/j.erss.2017.06.006

Chabay I, Koch L, Martinez G, Scholz G (2019) Influence of narratives of vision and identity on collective behavior change. Sustainability 11(20):5680

Crutzen PJ (2002) Geology of mankind. Nature 415(6867):23. https://doi.org/10.1038/415023a

David Tàbara J, Jäger J, Mangalagiu D, Grasso M (2018) Defining transformative climate science to address high-end climate change. Reg Environ Change. https://doi.org/10.1007/s10113-018-1288-8

de Vries BJM (2012) Sustainability science. Cambridge University Press, Cambridge. https://doi. org/10.1017/CBO9780511794469

Facer K (2011) Learning futures: education, technology, and social change. Routledge, Oxon. https://doi. org/10.4324/9780203817308

Falk JH (2005) Free-choice environmental learning: framing the discussion. Environ Educ Res 11(3):265-280. https://doi.org/10.1080/13504620500081129

Hennes T, Chabay I (2001) From looking environment to learning environment: the networked aquarium of the 21st century. Mar Technol Soc J 35(1):48-59

Honeyford MA, Boyd K (2015) Learning through play. J Adolesc Adult Lit 59(1):63-73. https://doi. org/10.1002/jaal.428

Ignatow G (2006) Cultural models of nature and society: reconsidering environmental attitudes and concern. Environ Behav 38(4):441-461. https://doi.org/10.1177/0013916505280791

Kahan DM, Braman D, Gastil J, Slovic P, Mertz CK (2007) Culture and identity-protective cognition: explaining the white-male effect in risk perception. J Empir Legal Stud 4(3):465-505. https://doi.org /10.1111/j.1740-1461.2007.00097.x

King Jr ML (1963) "I Have A Dream". March on Washington for Jobs and Freedom. US Government Archives, Washington, D.C.

Li H, Chabay I, Renn O, Weber A, Mbungu G (2015) Exploring smart grids with simulations in a mobile science exhibition. Energy Sustain Soc 5(1):1-8. https://doi.org/10.1186/s13705-015-0066-4

Miller TR, Wiek A, Sarewitz D, Robinson J, Olsson L, Kriebel D, Loorbach D (2014) The future of sustainability science: a solutions-oriented research agenda. Sustain Sci 9(2):239-246. https://doi. org/10.1007/s11625-013-0224-6

Rauschmayer F, Bauler T, Schäpke N (2015) Towards a thick understanding of sustainability transitions-linking transition management, capabilities and social practices. Ecol Econ 109:211-221. https://doi.org/10.1016/j.ecolecon.2014.11.018

Raworth K (2017) A doughnut for the Anthropocene: humanity's compass in the 21st century. Lancet Planet Health 1(2):e48-e49. https://doi.org/10.1016/s2542-5196(17)30028-1

Renn O (2019) Gefühlte Wahrheiten Orientierung in Zeiten Postfaktischer Verunsicherung. Verlag Barbara Budich, Leverkusen, Germany

Renn O, Klinke A, van Asselt M (2011) Coping with complexity, uncertainty and ambiguity in risk governance: a synthesis. Ambio 40(2):231-246. https://doi.org/10.1007/s13280-010-0134-0

Rockström J, Steffen W, Noone K, Lambin E, Lenton TM, Scheffer M, Folke C et al (2009) Planetary boundaries: exploring the safe operating space for humanity. Ecol Soc 14(2):32

Rogoff B, Callanan M, Gutiérrez KD, Erickson F (2016) The organization of informal learning. Rev Res Educ 40(1):356-401. https://doi.org/10.3102/0091732X16680994

Saad A (2018) Pathways of harm: the consequences of Trump's withdrawal from the Paris climate agreement. Environ Justice 11(1):47-51. https://doi.org/10.1089/env.2017.0033

Selby J (2019) The Trump presidency, climate change, and the prospect of a disorderly energy transition. Rev Int Stud 45(3):471-490. https://doi.org/10.1017/S0260210518000165

Somers MR (1994) The narrative constitution of identity: a relational and network approach. Theory Soc 23(5):605-649. https://doi.org/10.1007/BF00992905

Steffen W, Broadgate W, Deutsch L, Gaffney O, Ludwig C (2015a) The trajectory of the anthropocene: the great acceleration. Anthr Rev 2(1):81-98. https://doi.org/10.1177/2053019614564785

Steffen W, Katherine Richardson J, Rockstrom SE, Cornell IF, Bennett EM, Biggs R et al (2015b) Planetary boundaries: guiding human development on a changing planet. Science 347(6223):1259855. https://doi.org/10.1126/science.1259855

Trapenberg Frick K, Weinzimmer D, Waddell P (2015) The politics of sustainable development opposition: state legislative efforts to stop the United Nation's agenda 21 in the United States. Urban Stud 52(2):209-232. https://doi.org/10.1177/0042098014528397 
TWI2050-The World in 2050 (2018) Transformations to achieve the sustainable development goalsreport prepared by The World in 2050 Initiative. Int Inst Appl Syst Anal. https://doi.org/10.22022/ TNT/07-2018.15347

United Nations General Assembly (2015) Transforming our world: the 2030 agenda for sustainable development. https://Sustainabledevelopment.Un.Org/Content/Documents/7891TransformingOurWorld. pdf. https://doi.org/10.1007/s13398-014-0173-7.2

Westerhoff L, Robinson J (2013) 'Practicing' narratives: exploring the meaning and materiality of climate change. In: Transformation in a changing climate, University of Oslo, pp 202-211. www.iss. uio.no/transformation

White DD, Wutich A, Larson KL, Gober P, Lant T, Senneville C (2010) Credibility, salience, and legitimacy of boundary objects: water managers' assessment of a simulation model in an immersive decision theater. Sci Public Policy. https://doi.org/10.3152/030234210X497726

Worchel S, Coutant D (2008) It takes two to tango: relating group identity to individual identity within the framework of group development. Blackwell handbook of social psychology: group processes. Blackwell Publishers Ltd, Oxford, pp 461-481. https://doi.org/10.1002/9780470998458.ch19

World Commission on Environment and Development (1987) Brundtland report: our common future. Report of the World Commission on Environment and Development: Our Common Future

Publisher's Note Springer Nature remains neutral with regard to jurisdictional claims in published maps and institutional affiliations. 